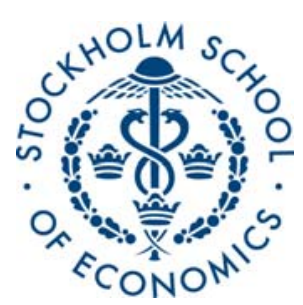

\title{
ASIAN SOVEREIGN DEBT AND COUNTRY RISK
}

Anders C. Johansson

Stockholm School of Economics

\section{CERC Working Paper 11}

December 2009

Postal address: P.O. Box 6501, S-113 83 Stockholm, Sweden.

Office address: Holländargatan 30 Telephone: +46 87369360 Telefax: +46 8313017

E-mail: japan@hhs.se Internet: http://www.hhs.se/cerc 


\title{
Asian Sovereign Debt and Country Risk
}

\author{
Anders C. Johansson* \\ Stockholm School of Economics
}

\begin{abstract}
This paper analyzes systematic risk of sovereign bonds in four East Asian countries: China, Malaysia, Philippines, and Thailand. A bivariate stochastic volatility model that allows for time-varying correlation is estimated with Markov Chain Monte Carlo simulation. The volatilities and correlation are then used to calculate the time-varying betas. The results show that country-specific systematic risk in Asian sovereign bonds varies over time. When adjusting for inherent exchange rate risk, the pattern of systematic risk is similar, even though the level is generally lower. The findings have important implications for international portfolio managers that invest in emerging sovereign bonds and those who need benchmark instruments to analyze risk in assets such as corporate bonds in the emerging Asian financial markets.
\end{abstract}

Keywords: Asia; sovereign bonds; systematic risk; stochastic volatility; Markov Chain Monte Carlo

JEL Classification: C32; F31; G12; G15

\footnotetext{
* E-mail: anders.johansson@hhs.se. Stockholm School of Economics, P.O. Box 6501, 11383 Stockholm, Sweden. Financial support from the Bank of Sweden Tercentenary Foundation, the Swedish Foundation for International Cooperation in Research and Higher Education, and the Swedish School of Advanced Asia-Pacific Studies (SSAAPS) is gratefully acknowledged.
} 


\section{Introduction}

This study takes a close look at sovereign bond markets and how systematic risk behaves over time in four Asian countries. Bond markets have grown in the region for a number of reasons. From a macroeconomic perspective, well-developed domestic bond markets are important for financial stability. Following the Asian financial crisis, regional governments came to the conclusion that a major part of the reason for why the crisis became so severe was that of the so-called double mismatch problem, i.e. domestic companies borrowed short term in foreign currencies and used the capital to fund long term investments in local currencies (Johansson, 2008). The crisis also highlighted the overreliance on domestic banks for the financing of new projects combined with poor banking supervision. In the wake of the crisis, the Asian countries initiated a region-wide cooperative effort with the aim to develop the domestic bond markets. Using a regional approach, they hope to overcome problems emerging economies face when developing their bond markets, including scale inefficiency. Other issues they want to solve through regional cooperation include how to best strengthen investor and creditor rights and to develop a more effective bond market infrastructure (Eichengreen, Borensztein and Panizza, 2006). By developing domestic bond markets, the Asian countries may thus decrease the risks of double mismatch problems and the overreliance on bank funding in the domestic economy. There are also other significant benefits of well-functioning bond markets. They provide an alternative source of funding for private as well as public investments. In terms of portfolio and wealth management, they also provide alternative ways to invest, something that is extremely important as many of the Asian countries develop their social welfare and pension systems and high domestic saving rates mean that private investors are looking for complements to risky domestic stock markets and bank accounts with very low yields. Furthermore, a well-functioning government bond market enables the creation of a term structure of interest rates that can be used as a benchmark for investments in general. 
Finally, government bonds are often used as proxy for the risk-free rate in different capital asset pricing models and thus play an important role in asset pricing.

Even though local bond markets are clearly of significant importance, and even though the market capitalization of international bond markets matches that of international equity markets, the literature on systematic risk in bond markets is surprisingly small. Sovereign bonds are usually seen as benchmark instruments; they are claims on the respective government that issues them, which means that their value is only dependent on countryspecific systematic factors (Dittmar and Yuan, 2008). This study analyzes systematic market risk for sovereign bonds in Asia. We apply a bivariate stochastic volatility model to each of the bond markets and the world equity market. To estimate the model, we perform a Markov Chain Monte Carlo (MCMC) simulation. We then use the time-varying market volatilities and correlation to compute time-varying betas for the different bond markets. This study contributes to the literature in several ways. This is, to the best of our knowledge, the first study that identifies time-varying country-specific systematic risk in emerging markets using time-varying betas for sovereign bonds. We also take a closer look at how exchange rates influence time-varying systematic risk by comparing time-varying betas for standard USdollar denominated indices and betas based on indices re-denominated in local currencies. Our results show that systematic risk in Asian markets varies significantly over time, something that has a direct and important effect on all financial assets in these markets. The risk patterns indicate that there are periods of high systematic risk followed by long periods of lower risk levels. When taking exchange rate risk into account through re-denomination of the indices into local currencies, it is shown that the time-varying risk patterns are similar, but that the general risk level is significantly lower in all four markets.

The rest of this article is organized as follows: In Section 2, we discuss the CAPM and time-varying systematic risk. We also discuss risk in sovereign debt markets. 
Section 3 introduces the bivariate stochastic volatility model that is used to estimate the timevarying volatilities and correlations of each of the bond markets and the world market. This section also gives a short description of MCMC simulation and how it is used to estimate stochastic volatility models. Section 4 first introduces the data and then presents the empirical results. Finally, Section 5 concludes the paper.

\section{Time-Varying Systematic Risk and Debt Markets}

The CAPM is one of the most important works of modern finance theory. It originated in the end of the 1950s, when Markowitz (1959) and Tobin (1958) published their work on meanvariance selection. Soon after, Sharpe (1964) and Lintner (1965) used this concept when they published an equilibrium model for capital markets. The model ties the return of a single asset to that of the market and shows that individual assets earn a risk premium over the risk-free rate that is related to the market risk premium. Later studies have shown that betas tend to fluctuate over time. Early research on this phenomenon includes Fabozzi and Francis (1978), Sunder (1980), and Bos and Newbold (1984). Bodurtha and Mark (1991) provide a good overview of this literature. Later and more comprehensive studies on the US market include Harvey (1989) and Jagannathan and Wang (1996). Brooks, Faff and McKenzie (2002) estimate conditional betas for a number of industrialized countries. Johansson (2009d) performs a related study on a large set of emerging equity markets. Both studies show that international stock markets exhibit varying systematic risk.

There are a number of reasons for why it is important to study systematic risk in international debt markets. Davis (2005) brings up four such reasons. First, there is no uncertainty related to future cash flows from government bonds. This means that the level of systematic risk and changes in betas must be due to country-wide changes in the required rates of return or general changes in the relationship between expectations on future cash flows on different assets and the required rate of return. As Dittmar and Yuan (2008) point 
out, sovereign bonds are usually seen as benchmark instruments. Their value is only dependent on country-specific systematic factors because they are claims on the government that issues them. Emerging sovereign bonds are thus influenced by general macroeconomic risks. Here, it should be noted that default risk is significant for most countries, which means that their sovereign bond prices also include the possibility of default. ${ }^{2}$ Second, corporate bonds may exhibit significant systematic risk, something that has not been researched thoroughly. By analyzing the inherent systematic risk in benchmark assets such as sovereign bonds, we thus take a step towards a better understanding of how corporate bond prices incorporate systematic risk. Third, a risk-free rate based on short-term government bond yields is often used in the CAPM framework. This makes it important to fully understand the inherent systematic risk in such interest rates. Fourth, there is an increasing trend towards investing across multiple asset classes in international financial markets. This means that systematic risk not only in international equity markets but also debt markets is important for international investors.

Do we expect debt betas to be positive or negative? Davis (2005) points out that debt betas can be expected to be positive. However, this is not always the case. The comovements in stocks and bonds have been debated in many articles. Barsky (1989) discusses the relationship between the two asset classes using a consumption-based model. He argues that stocks and bonds may or may not move together depending on the general level of risk aversion. Shiller and Beltratti (1992) argue that movements in stocks and bonds should be negatively correlated since the discount rate has different effects on them. In a related study,

\footnotetext{
${ }^{2}$ Reinhart, Rogoff and Savastano (2003) find that past defaults are a good indicator of a sovereign's ability to bear debt without the high risk of future default. Moreover, it is often argued that reputation can be a strong motivating factor for sovereigns to avoid default (e.g. Eaton and Gersovitz, 1981; Grossman and Van Huyck, 1988; Atkeson, 1991). Interestingly enough, most countries in East Asia have a very strong record with few, if any, defaults. For instance, while countries such as Malaysia, Singapore, South Korea, and Thailand have been tested in times of great financial turmoil, they have yet to default on their sovereign bonds (Reinhart and Rogoff, 2004). However, while research indicates that a history of default plays a major role for the risk of default, this is not the only determinant for future defaults. For instance, inflationary levels are also related to default risk (Reinhart, Rogoff and Savastano, 2003). The existence of default risk complicates the usage of sovereign bonds as risk-free assets in asset pricing models.
} 
Johansson (2009b) uses a multivariate conditional volatility framework to analyze timevarying correlations between stocks and bonds in emerging markets. The results indicate that stock-bond correlations tend to vary over time and can take both positive and negative values. These results tell us that we can expect debt betas in Asian markets to be both positive and negative and that they most probably vary significantly over time.

\section{Methodology}

This section introduces the estimation procedure that is used to extract the time-varying betas. We first go over the concept of stochastic volatility and then introduce the bivariate stochastic volatility model that will be applied on the bond indexes and the world market index. We also make a brief introduction to MCMC and how it is used to estimate the parameters in the volatility model.

\subsection{Stochastic Volatility}

Even though the traditional ARCH/GARCH group of models is very popular in empirical studies of market volatility, stochastic volatility models are quickly gaining ground as a viable alternative. One of the reasons for why stochastic volatility models are growing in popularity is that they can be seen as being more closely related to fundamental microeconomic and financial theory (see, e.g. Tauchen and Pitts, 1983, and Andersen, 1996, for discussions on how stochastic volatility modeling is related to theory). Another reason for its growing popularity is that studies show that stochastic volatility models perform well relative to GARCH models when one wants to estimate time-varying volatility. In studies by Danielsson (1994) and Kim, Shephard and Chib (1998), it is shown that stochastic volatility models outperform GARCH models when it comes to in-sample fitting. Similarly, Yu (2002) uses the two approaches for out-of-sample forecasting and report that a stochastic volatility model performs better than GARCH models. As a result of these arguments in favor of stochastic 
volatility models, such models have been used in many different applications in empirical finance. Also, stochastic volatility specifications are commonly used when modeling financial derivatives. The often cited models by Hull and White (1987) and Heston (1993) both make use of a stochastic volatility framework to model and estimate stock options. Stochastic volatility models have also been used in studies on optimal asset allocation. One example is Han (2006), who develops a multivariate stochastic volatility model and uses it to manage asset portfolios. Finally, in an article closely related to this study, Johansson (2009d) uses a bivariate stochastic volatility model to estimate time-varying betas in a large set of emerging markets.

One problem in the early stages of the stochastic volatility literature was how to overcome the challenge of model estimation. Standard ARCH/GARCH models specify the conditional volatility as a deterministic process that depends on previous shocks and volatility, which means that they are easily estimated using standard maximum likelihood estimation. Stochastic volatility models, on the other hand, specify the time-varying volatility as a latent random process. This means that a basic maximum likelihood approach is not suitable since we cannot obtain an explicit expression for the likelihood function (Shephard, 2005; Johannes and Polson, 2006). As a result, a number of different estimation procedures have been proposed to overcome this problem, including quasi-maximum likelihood (QML), general method of moments (GMM), efficient method of moments (EMM), and simulated maximum likelihood (SML) and MCMC simulation. The first multivariate stochastic volatility model was presented by Harvey, Ruiz and Shephard (1994). Their original model can be seen as an extension of the univariate stochastic volatility model and it does not include correlation in either returns or volatilities. A few recent papers on multivariate stochastic volatility allow for the correlation among assets to vary over time. For instance, Asai and McAleer (2009) suggest a model that allows for a larger number of variables to be 
included. Yu and Meyer (2006) instead propose a model that can be used in a bivariate setup. Johansson (2009a) use a modified version of Yu and Meyer (2006) to estimate time-varying betas in stock markets. In this paper, the bivariate dynamic correlation model proposed by $\mathrm{Yu}$ and Meyer (2006) is used. The next section introduces the model and then discusses how to estimate it using a MCMC simulation procedure.

\subsection{The Model}

In this section, we present the bivariate stochastic volatility model that we then use to estimate time-varying betas for four Asian bond markets. The model is from Yu and Meyer (2006) and combines two important features: exponential stochastic volatility and dynamic correlation. The model can be written as:

$$
\begin{aligned}
& y_{t}=\Omega_{t} \varepsilon_{t}, \quad \varepsilon_{t} \sim N\left(0, \Sigma_{\varepsilon, t}\right), \\
& \Sigma_{\varepsilon, t}=\left(\begin{array}{cc}
1 & \rho_{t} \\
\rho_{t} & 1
\end{array}\right), \\
& h_{t+1}=\gamma_{0}+\operatorname{diag}\left(\gamma_{11}, \gamma_{22}\right)\left(h_{t}-\gamma_{0}\right)+\eta_{t}, \quad \eta_{t} \sim N\left(0, \operatorname{diag}\left(\sigma_{1, t}^{2}, \sigma_{2, t}^{2}\right)\right),
\end{aligned}
$$

with $h_{0}=\gamma_{0}$. Equation (2) shows that we expect the correlation between the two variables to vary over time. We follow Tsay (2005) and Christodoulakis and Satchell (2002) when we model the time-varying correlation. Basically, we estimate an $\mathrm{AR}(1)$ process for the correlation function. However, $\rho_{t}$ needs to be bounded. We therefore use a Fischer transformation and define the correlation process by

$$
z_{t+1}=\delta_{0}+\delta_{1}\left(z_{t}-\delta_{0}\right)+\sigma_{\rho} \vartheta_{t}, \quad \vartheta \sim N(0,1), \quad \rho_{t}=\frac{\exp \left(z_{t}\right)-1}{\exp \left(z_{t}\right)+1}
$$

with $z_{0}=\delta_{0}$. The Fischer transformation clearly bounds $\rho_{t}$ by -1 and 1 . One drawback with this model is that it is difficult to generalize to higher dimensions. Yu and Meyer (2006) suggest a solution for situations where the number of variables, $N$, is larger than two. Inspired 
by Engle (2002), Yu and Meyer (2006) show one possible solution to higher dimensional problems. Also, as mentioned earlier, Asai and McAleer (2009) suggest an alternative dynamic correlation model for multivariate stochastic volatility. There are thus several plausible solutions when facing a situation with $N>2$. However, since we will use the model in a bivariate setting, we do not generalize the correlation structure further here.

It is plausible to assume that the correlation between a world stock index and different country indexes for bonds changes significantly over time. Related literature, especially studies on emerging markets, supports this assumption. Indexes from the same asset class as well as across asset classes tend to exhibit time-varying correlation in these markets. For instance, Johansson (2009d) shows that the correlation between emerging stock markets and the world market changes over time, in some cases dramatically. Similarly, Johansson (2008) shows that the correlation pattern between different Asian bond markets tends to change over time. Finally, Johansson (2009b) analyzes the relationship between stocks and bonds in emerging countries. The results indicate that the cross-asset correlation changes considerably over time, especially during times of market turmoil.

Estimating a stochastic volatility model is not as straightforward as estimating a GARCH model. Since the latent variable, i.e. volatility, is modeled as a stochastic process, there is no closed form for the likelihood function of the model. It is therefore not suitable to apply a standard maximum likelihood function estimation procedure on stochastic volatility models. As mentioned earlier, several different solutions to this problem have been proposed in the literature on stochastic volatility modeling. Studies on the estimation of stochastic volatility models have been in favor of MCMC. For instance, Jacquier, Polson and Rossi (1994) show that the MCMC approach results in better estimates than several alternative methods. We therefore use a MCMC procedure when estimating the bivariate stochastic volatility model presented above. In the Bayesian framework that MCMC is built upon, both 
the parameters and the latent variables are treated as random variables. Estimating models using MCMC rests on the so-called Clifford-Hammerslev theorem. The theorem says that the joint distribution of parameters $(\theta)$ and latent variables $(x)$ given observed prices, $f(\theta, x \mid y)$, is completely characterized by the conditional distribution of the latent variables, $f(x \mid \theta, y)$, and the conditional distribution of the parameters, $f(\theta x, y)$. Here, $y$ is the set of observable variables. Bayes' rule states that the posterior distribution is related to the prior distribution through

$$
f(\theta, x \mid y)=\frac{f(y \mid x, \theta) f(x \mid \theta)}{f(y)}
$$

where $f(\theta, x \mid y)$ is the posterior distribution, $f(y \mid x, \theta)$ is the likelihood function, $f(x \mid \theta)$ is the prior distribution for the latent variables, $f(\theta)$ is the prior distribution for the parameters, and $f(y)$ is the density function of the observed variables. Since $y$ can be seen as constant, its density can also be seen as constant. This means that the expression can be simplified to $f(\theta, x \mid y) \propto f(y \mid x, \theta) f(x \mid \theta) f(\theta)$. In Bayesian inference, the prior distribution is specified independently from the data sample, which means that MCMC and Bayesian inference in general is based on the data as well as the prior knowledge of the parameters. MCMC simulation solves the problem with the unknown specification of a high-dimensional distribution by constructing Markov chains with stationary distributions equal to the target densities. $^{3}$

\section{Empirical Results}

In this section, we begin by describing the data for the four Asian bond markets. The bivariate stochastic volatility model described above is then applied to each of the four markets and the time-varying volatilities and correlation are used to calculate time-varying betas.

\footnotetext{
${ }^{3}$ For a more detailed description of MCMC simulation and how it can be used to estimate multivariate stochastic volatility models, see Yu and Meyer (2006).
} 


\subsection{Data}

The bond market data in this paper are from the JP Morgan Emerging Market Bond Index (EMBI) Global series. The EMBI is the most commonly used benchmark index series for emerging bond markets. It is constructed from US dollar-denominated sovereign bonds, the most liquid form of emerging market sovereign bonds. The MSCI World equity index is used as the market portfolio. The data are sourced from Datastream and are gathered at weekly frequency from December 12, 1993 to December 31, 2008. The data for the Philippine market is complete, while the other three indexes are somewhat shorter. Moreover, there was only available data for Thailand's index up to mid-2006. The continuously compounded percentage return of each index series is calculated as the log of the price differences $\left(R_{i, t}=\right.$ $\left.100 * \log \left[P_{i, t} / P_{i, t-1}\right]\right)$. The log returns for each of the four markets are shown in Figure 1 . The figure show signs of significant volatility clustering, indicative of heteroscedasticity.

\section{[FIGURE 1 HERE]}

Even though the EMBI Global indices are seen as benchmarks for investments in emerging bond markets, they are composed of US dollar-denominated sovereign bonds. This means that they are exposed to exchange rate risk. Emerging market exchange rates tend to be significantly more volatile than those of developed countries. Furthermore, Ilmanen (1995) highlights the importance of separating the two sources of risk since exchange rates exhibit higher volatility than bonds in international markets. Overall, it is clear that exchange rate movements have a significant effect on foreign currency-denominated bond betas in emerging markets. On the other hand, to hedge currency risk is an inexpensive and straightforward procedure in most cases, which means that it is possible to decrease exchange rate risk. To study how exchange rate movements influence bond betas, we re-denominate the bond indices 
using the respective currency in the four countries. In the following two sections, we thus estimate bond betas for both US-dollar-denominated and local-currency denominated indices. Table 1 reports summary statistics for each of the four bond markets using both US-dollar and local-currency denomination. The mean returns for the four bond market are similar, ranging from weekly returns of 0.138 to 0.179 percent. Unconditional standard deviation indicates that the Philippine is the most volatile market, while the Chinese market exhibits a modest level of volatility for the sample period. Finally, the Ljung-Box test on squared values and the Lagrange multiplier test for ARCH effects indicate that the series exhibit significant heteroscedastic features, as noted earlier.

\section{[TABLE 1 HERE]}

\subsection{Time-Varying Betas for Sovereign Bonds}

Having looked at the basic features of the data, we now turn to the estimation of the bivariate stochastic volatility model for each of the four bond markets. Before the estimation, we need to specify the prior distributions for the parameters. The priors are based on earlier studies that utilize similar models (e.g. Yu and Meyer, 2006; Johansson, 2009d). The complete set of prior distributions for the parameters is: 
$\gamma_{10} \sim N(0,10)$

$\gamma_{10} \sim N(0,10)$

$\gamma_{11}^{*} \sim \operatorname{beta}(20,1.5)$, where $\gamma_{11}^{*}=\left(\gamma_{11}+1\right) / 2$

$\gamma_{22}^{*} \sim \operatorname{beta}(20,1.5)$, where $\gamma_{22}^{*}=\left(\gamma_{22}+1\right) / 2$

$\sigma_{1}^{2} \sim$ Inverse-Gamma(2.5, 0.025)

$\sigma_{2}^{2} \sim$ Inverse-Gamma $(2.5,0.025)$

$\delta_{0} \sim N(0.7,10)$

$\delta_{1}^{*} \sim \operatorname{beta}(20,1.5)$, where $\delta_{1}^{*}=\left(\delta_{1}+1\right) / 2$

$\sigma_{\rho}^{2} \sim$ Inverse-Gamma(2.5, 0.025)

The priors are somewhat informative, but are quite general and thus do not constrain the outcome of the simulation very much. The MCMC simulation procedure is initiated with 10,000 burn-ins, which we then discard. The following 40,000 draws are then used for inference on the model parameters. The estimated parameters are presented in terms of their location and dispersion measures. The mean, standard deviation, and the $95 \%$ credible intervals of the posterior distributions are shown in Table 2. Most of the constants in the volatility specification $\left(\gamma_{10}\right.$ and $\left.\gamma_{20}\right)$ are not significantly different from zero, as can be seen in the $95 \%$ interval values. The estimated values for $\gamma_{11}$ and $\gamma_{22}$ show that volatility is highly persistent, with values just below one in almost all cases. Earlier studies indicate that volatility can be very persistent in emerging bond markets (e.g. Johansson, 2009b), thus supporting the results in this study. Furthermore, the estimate values for $\delta_{1}$ are all close to one, suggesting a high persistence in correlation between each of the four sovereign bond markets and the world equity index.

[TABLE 2 HERE] 
Before we analyze the volatility and correlation patterns, we first look at the simulation output in closer detail. The trace plots for the model parameters are presented in Figure 2 for the bivariate estimation that includes China and the world market. Table 3 reports the Geweke Zscores for each of the model parameters in all four simulations. Overall, the test results indicate that the Markov chains are converging sufficiently well. The Z-scores are either smaller than the critical values or very close to them (2.56 is the $1 \%$ critical value and 1.96 is the $5 \%$ critical value). We can therefore conclude that the MCMC simulation results in acceptable estimates of the model parameters.

[FIGURE 2 HERE]

[TABLE 3 HERE]

The time-varying volatilities in each of the four Asian bond markets are presented in Figure 3. The Chinese market experienced a relatively stable volatility pattern across the sample, except for a spike during the Asian financial crisis and a more severe spike during the global financial crisis in 2008. Thailand and Malaysia were two of the most severely affected countries during the Asian financial crisis in 1997-1998, something that is shown in the volatility pattern for the countries' sovereign bond markets. Unfortunately, the sample for the Thai sovereign bond market is limited to 2006. The Malaysian market was affected in a pattern similar to that of the Chinese market during 2008. The Philippine sovereign bond markets also experienced a peak in 1998 together with several similar peaks throughout the sample. However, similar to China, the most extreme volatility occurred during the international financial crisis in 2008. 


\section{[FIGURE 3 HERE]}

The dynamic correlation patterns between each of the four sovereign bond markets and the world market are presented in Figure 4. All four markets experienced large changes in correlation against the world market during the sample period, with dips during 2001-2002. For China, Malaysia, and Thailand, correlation shifted between positive and negative values. Overall, all four East Asian sovereign bond markets exhibit surprisingly high but also considerably shifting levels of correlation throughout the sample period.

\section{[FIGURE 4 HERE]}

Finally, the time-varying betas are computed, using the time-varying volatility and the timevarying correlation, or $\beta_{i, t}=\rho_{i m, t} \sigma_{i, t} / \sigma_{m, t}$, where $\beta_{i, t}$ is the time-varying beta for sovereign bond market $i, \sigma_{i, t}$ is the time-varying standard deviation of market $i, \rho_{i m, t}$ is the time-varying correlation between market $i$ and the world market, and $\sigma_{m, t}$ is the time-varying standard deviation of the world market. The time-varying betas are presented in Figure 5. It is clear that the systematic market risk as measured by sovereign bond betas varies considerably over time. Also, the patterns differ among the four markets. China's systematic risk exhibits decreasing tendencies throughout the sample. For Malaysia, there is a very large spike during the Asian financial crisis, after which the beta levels out around zero. The shape of the timevarying beta for the Philippine sovereign bond markets differs the most compared to the other markets, with regular spikes throughout the sample period. Finally, the limited sample of the Thai sovereign bond markets shows signs of a rapid increase in overall country risk during the Asian financial crisis, after which the sovereign bond beta came down to levels around zero. Since it is often argued that sovereign bond markets capture country-specific macroeconomic 
and default risks, these time-varying betas give us a clear picture of how the market sees these country-specific risks for each of the four markets.

\section{[FIGURE 5 HERE]}

Table 4 presents summary statistics for the four time-varying betas. The mean is small for all four series, especially for China and Malaysia. Thailand and the Philippines experience periods with high country-specific risk, with sovereign bond betas well over one. Furthermore, all series except for that of the Philippines have negative minimum values. All four series are positively skewed and the Thai and Philippine series show signs of significant kurtosis. The Jarque-Bera test rejects normality in all four series and the Ljung-Box statistic shows significant serial correlation in both first and second moments. The LM ARCH test supports the results of the Ljung-Box test on the squared time series, indicating the presence of significant volatility clustering. The significant presence of autocorrelation in both the first and second moments suggests that country risk as measured by sovereign bond betas is predictable.

[TABLE 4 HERE]

This section has focused on estimating risk in Asian sovereign bond markets. The natural next step is to ask whether we need to look at additional potential sources of risks that are priced in sovereign bond markets. There is one obvious source of risk that is perhaps especially important when analyzing emerging markets: exchange rate movements. Exchange rates in developing countries tend to be very volatile and can at times have higher standard deviations than sovereign bonds. Even though the JP Morgan EMBI Global index is considered to be 
composed of assets that are the most liquid in emerging debt markets, these assets are all denominated in US dollars. This means that movements in the local currency against the US dollar may well constitute a significant part of the total country-specific risk as measured by sovereign bond betas. In the next section, we adjust each of the four Asian bond markets so that they are measured in local currency, re-estimate the stochastic volatility model, and compute the time-varying betas. We then compare the new betas with the original set of betas computed in this section.

\subsection{Local-Currency Beta Estimations}

Having changed the denomination of the bond indices into local currency, we re-estimate the stochastic volatility model with the local currency indices and the world market index. The results of the new estimations are presented in Table 5. Again, the estimated values for $\gamma_{11}$ and $\gamma_{22}$ are close to but smaller than one in all cases, showing that volatility is very persistent in all four sovereign bond markets as well as the world equity market.

\section{[TABLE 5 HERE]}

Instead of going into detail on the patterns of time-varying volatilities and correlations, we choose to focus on the time-varying betas for the bond markets. Applying the same procedure as in the previous section, we use the time-varying standard deviations and correlations to compute the betas, which are presented in Figure 6. First, the patterns for the Chinese bond market are almost identical when using each of the two currency-denominated indices. This is a natural result, given that China has a fixed exchange rate regime. ${ }^{4}$ Similarly, the Malaysian bond market show very similar time-varying beta patterns, especially from 1998 and forward.

\footnotetext{
${ }^{4}$ Beginning in 2005, the Chinese government began to allow the renminbi to move moderately against other currencies (Johansson, 2009c). However, these changes are limited to a narrow band, which means that the exchange rate impact on the bond beta is quite limited, as seen when comparing Figures 5 and 6.
} 
This is also expected, since the Malaysian government imposed capital controls and maintained a pegged ringgit against the US dollar as a response to the regional financial crisis starting in 1997. For the other two markets, there are more significant changes. For the Philippine time-varying sovereign bond beta, the patterns in the two figures resemble each other somewhat. However, when looking at the level, it is clear that the re-denomination of the index into local currency results in a much lower level of beta over time. The same goes for Thailand's bond index, which exhibits much lower beta levels over the period of its existence.

\section{[FIGURE 6 HERE]}

To shed further light on the exchange rate effects on sovereign bond betas, the summary statistics of the new time-varying beta series are presented in Table 6. Supporting the discussion based on Figure 6, the mean levels are much lower for the Philippine and Thai markets. The Chinese and Malaysian time-varying sovereign bond betas also have lower means, most likely a result of the fact that the Chinese exchange rate is allowed to move against the US dollar and that the Malaysian ringgit experienced significant volatility changes during the financial crisis in 1997-1998. The Malaysian ringgit was traded as a free float currency the years before the financial crisis hit the region. During the crisis, the ringgit depreciated with as much as 50\% against the US dollar. In September 1998, the central bank pegged it at 3.80 to the US dollar. It was not until in 2005, right after the Chinese government published its change in exchange rate policy, that the Malaysian central bank changed the exchange rate, now instead using a managed float exchange rate regime. These developments in the exchange rates most likely resulted in an increase in sovereign bond market risk when measured in US dollar, since such indices implicitly includes exchange rate risk. 
[TABLE 6 HERE]

Comparing Figures 5 and 6 as well as Tables 4 and 6, it is easy to see the exchange rate effect on country-specific risk as measured by the time-varying beta of sovereign bond markets. Using the adjusted indices thus allows us to estimate and analyze country-specific risk due to macroeconomic features and default risk based on sovereign bond markets. The countryspecific risk as measured by time-varying sovereign bond betas can be used in a number of different ways when analyzing factors that cause risk in other asset classes, such as corporate bonds. The results also suggest that it may be inappropriate to use government bonds as measures of the risk-free rate when applying the standard CAPM to different assets. Our findings support those of Davis (2005), who found that Australian government bond betas vary significantly over time and that they are positive most of the time.

\section{Conclusions}

This study has analyzed systematic country risk of Asian sovereign bond markets. Analyzing the risk in sovereign bonds improves our understanding of systematic risk in general and can help us understand inherent risk in other assets in the same country. The paper looks at four Asian sovereign debt markets: China, Malaysia, Philippines, and Thailand. A bivariate stochastic volatility model is used to compute the time-varying volatilities and correlation between each of the bond portfolios and the world market. These are then used to compute the time-varying beta. Betas of sovereign debt markets allow us to study the movements in country-specific risk over time. The four countries included in this sample are perhaps especially interesting since they were all affected by the Asian financial crisis, albeit in very different ways. The time-varying beta patterns indicate that country-specific systematic risk varies significantly over time when sovereign debt is used in the analysis. During the Asian 
financial crisis, betas in all four markets increased significantly. In the aftermath of the crisis, the risk level went down and systematic risk fluctuated around levels close to zero and in some of the markets below zero.

Even though the JP Morgan EMBI Global indices used in this study are arguably the most commonly used benchmarks for investors in emerging debt markets, they are denominated in US dollars. This means that movements in the benchmark indices are affected by exchange rate movements. Since exchange rates in developing countries are prone to be volatile, it is natural to assume that the foreign currency-denomination results in a higher level of systematic risk. The indices are therefore adjusted with local exchange rates and the model is re-estimated for all four countries. The new betas exhibit similar patterns to the ones with US dollar-denominated indices. However, the general level of risk decreases significantly in all four markets. Since it is usually relatively inexpensive to hedge for exchange risk, it is preferable to use the local currency-denominated time-varying beta estimations as benchmarks when analyzing risk in other assets in these countries.

The results in this paper have several implications. First, they raise questions on whether it is prudent to use government bonds as proxies for the risk-free rate when applying the traditional CAPM model to different assets. Second, the significant changes in systematic risk over time show that it is important to allow for risk measures to change over time. This is arguably especially true for emerging markets, where market conditions are known to change quickly. Finally, the fact that there is a significant and time-varying systematic risk in bond portfolios has important implications for portfolio managers that use such assets when optimizing their portfolios. As the markets for government bonds in Asia continue to develop, it is important to understand how different government bonds behave and to measure the systematic risk in them. This paper is a first attempt to understand systematic risk in Asia's emerging markets using bond portfolios. There are several possible extensions for future 
research on emerging market sovereign debt and systematic risk. As these markets develop, further analysis on bonds with different maturities and currency denominations is important. Also, a more detailed analysis on emerging market corporate bonds and their respective timevarying betas could improve our understanding of the risk components in such assets. Another possible venue for future research is a closer examination of exchange rate exposure and its influence on emerging sovereign bond markets. 


\section{References}

Andersen, T., 1996. Return Volatility and Trading Volume: An Information Flow Interpretation of Stochastic Volatility, Journal of Finance, 51, 169-204.

Asai, M. \& McAleer, M., 2009. The Structure of Dynamic Correlations in Multivariate Stochastic Volatility Models, Journal of Econometrics, 150, 182-192.

Atkeson, A., 1991. International Lending with Moral Hazard and Risk of Repudiation, Econometrica, 59, 1069-1089.

Barsky, R.B., 1989. Why Don't the Prices of Stocks and Bonds Move Together?, American Economic Review, 79, 1132-1145.

Bodurtha, J. \& Mark, N., 1991. Testing the CAPM with Time-Varying Risk and Returns, Journal of Finance, 46, 1485-1505.

Bos, T. \& Newbold, P., 1984. An Empirical Investigation of the Possibility of Systematic and Stochastic Risk in the Market Model, Journal of Business, 57, 35-41.

Brooks, R.D, Faff, R.W. \& McKenzie, M.D., 2002. Time-Varying Country Risk: An Assessment of Alternative Modelling Techniques, European Journal of Finance, 8, 249-74.

Christodoulakis, G. \& Satchell, S. E., 2002. Correlated ARCH (CorrARCH): Modelling the Time-Varying Conditional Correlation between Financial Asset Returns, European Journal of Operational Research, 139, 351-370.

Danielsson, J., 1994. Stochastic Volatility in Asset Prices: Estimation with Simulated Maximum Likelihood, Journal of Econometrics, 64, 375-400.

Davis, K., 2005. The Systematic Risk of Debt: Australian Evidence, Australian Economic Papers, 44, 30-46.

Dittmar, R.F. \& Yuan, K., 2008. Do Sovereign Bonds Benefit Corporate Bonds in Emerging Markets?, Review of Financial Studies, 21, 1983-2014.

Eaton, J. \& Gersovitz, M., 1981. Debt with Potential Repudiation: Theoretical and Empirical Analysis, Review of Economic Studies, 48, 289-309.

Eichengreen, B., Borensztein, E., \& Panizza, U., 2006. A Tale of Two Markets: Bond Market Development in East Asia and Latin America, Unpublished manuscript, UC Berkeley and Inter-American Development Bank.

Engle, R.F., 2002. Dynamic Conditional Correlation: A Simple Class of Multivariate GARCH Models, Journal of Business and Economic Statistics, 17, 239-250.

Fabozzi, F.J. \& Francis, J.C., 1978. Beta as a Random Coefficient, Journal of Financial and Quantitative Analysis, 13, 101-115. 
Grossman, H. \& Van Huyck, J.B., 1988. Sovereign Debt as a Contingent Claim: Excusable Default, Repudiation, and Reputation, American Economic Review, 78, 1088-1097.

Han, Y., 2006. Asset Allocation with a High Dimensional Latent Factor Stochastic Volatility Model, Review of Financial Studies, 19, 237-271.

Harvey, C.R., 1989. Time-Varying Conditional Covariances in Tests of Asset Pricing Models, Journal of Financial Economics, 24, 289-317.

Harvey, A.C, Ruiz, E. \& Shephard, N., 1994. Multivariate Stochastic Variance Models, Review of Economic Studies, 61, 247-264.

Heston, S.L., 1993. A Closed-Form Solution for Options with Stochastic Volatility, Review of Financial Studies, 6, 327-343.

Hull, J. \& White, A., 1987. The Pricing of Options on Assets with Stochastic Volatilities, Journal of Finance, 42, 281-300.

Ilmanen, A., 1995. Time-Varying Expected Returns in International Bond Markets, Journal of Finance, 52, 481-506.

Jacquier, E., Polson, N. G. \& Rossi, P. E., 1994. Bayesian Analysis of Stochastic Volatility Models, Journal of Business and Economic Statistics, 12, 371-389.

Jagannathan, R. \& Wang, Z., 1996. The Conditional CAPM and the Cross-Section of Expected Returns, Journal of Finance, 51, 3-53.

Johannes, M. and Polson, N., 2006. MCMC Methods for Financial Econometrics, in AitSahalia, Y. \& Hansen, L. (eds), Handbook of Financial Econometrics, New York: Elsevier.

Johansson, A.C., 2008. Interdependencies among Asian Bond Markets, Journal of Asian Economics, 19, 101-116.

Johansson, A.C., 2009a. An Analysis of Dynamic Risk in the Greater China Equity Markets, Journal of Chinese Economic and Business Studies, 7, 299-320.

Johansson, A.C., 2009b. Emerging Stock and Bond Markets: Real Linkages or Just Exchange Rate Effects?, Unpublished manuscript.

Johansson, A.C., 2009c. Is U.S. Money Causing China's Output?, China Economic Review, 20, 732-741.

Johansson, A.C., 2009d. Stochastic Volatility and Time-Varying Country Risk in Emerging Markets, European Journal of Finance, 15, 337-363.

Kim, S., Shephard, N., \& Chib, S., 1998. Stochastic Volatility: Likelihood Inference and Comparison with ARCH Models, Review of Economic Studies, 65, 361-393.

Lintner, J., 1965. The Valuation of Risk Assets and the Selection of Risky Investment in Stock Portfolios and Capital Budgets, Review of Economics and Statistics, 47, 13-37. 
Markowitz, H., 1959. Portfolio Selection: Efficient Diversification of Investments, New York: John Wiley.

Reinhart, C.M. \& Rogoff, K.S., 2004. Serial Default and the 'Paradox' of Rich to Poor Capital Flows, American Economic Review, Papers and Proceedings, 94, 53-58.

Reinhart, C.M., Rogoff, K.S. \& Savastano, M.A., 2003. Debt Intolerance, Brookings Papers on Economic Activity, Spring (1), 1-74.

Sharpe, W., 1964. Capital Asset Prices: A Theory of Market Equilibrium under Conditions of Risk, Journal of Finance, 19, 425-442.

Shephard, N., 2005. General Introduction, in Shephard, N. (ed), Stochastic Volatility: Selected Readings, Oxford: Oxford University Press.

Shiller, R.J. \& Beltratti, A.E., 1992. Stock and Bond Yields - Can Their Comovements be Explained in Terms of Present Value Models?, Journal of Monetary Economics, 30, 25-46.

Sunder, S., 1980. Stationarity of Market Risk: Random Coefficients Tests for Individual Stocks, Journal of Finance, 35, 883-896.

Tauchen, G. \& Pitts, M., 1983. The Price Variability Volume Relationship on Speculative Markets, Econometrica, 51, 485-505.

Tobin, J., 1958. Liquidity Preference as Behavior towards Risk, Review of Economic Studies, 25, 65-85.

Tsay, R.S., 2005. Analysis of Financial Time Series, Second Edition, New York: John Wiley. Yu, J., 2002. Forecasting Volatility in the New Zealand Stock Market, Applied Financial Economics, 12, 193-202.

Yu, J. \& Meyer, R., 2006. Multivariate Stochastic Volatility Models: Bayesian Estimation and Model Comparison, Econometric Reviews, 25, 361-384. 
Figure 1. Sovereign Bond Returns
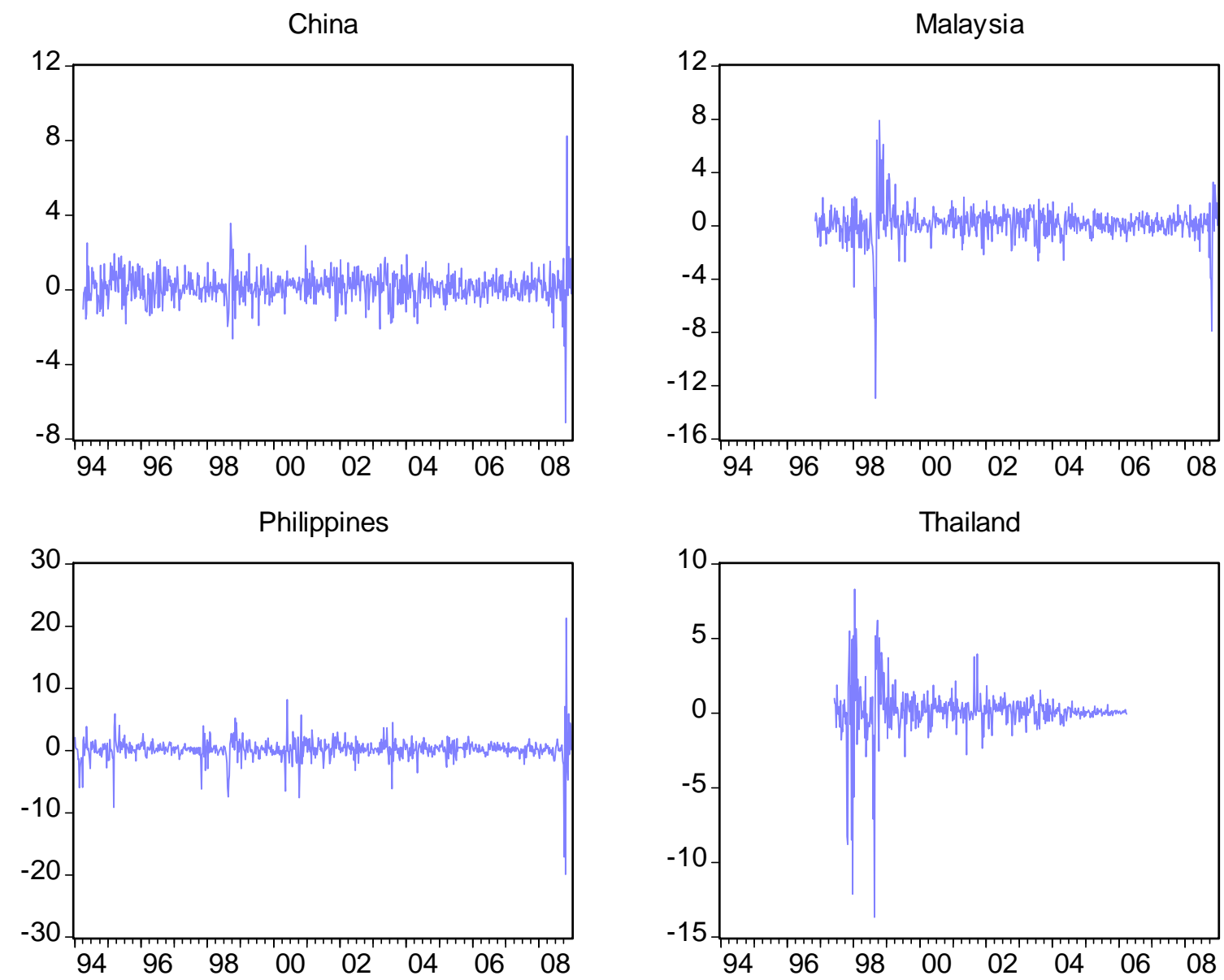
Figure 2. Trace Plots for Model Parameters - China
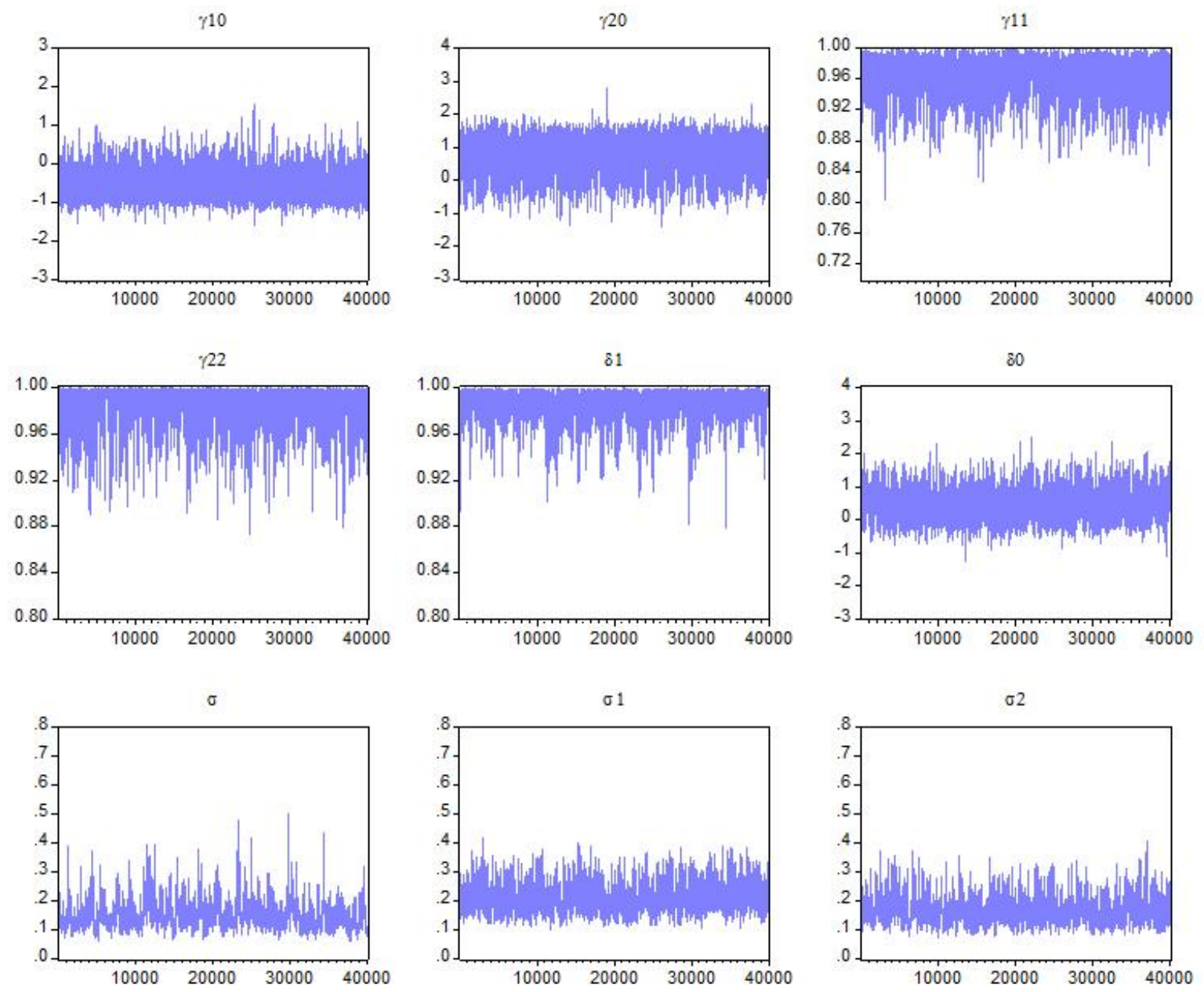
Figure 3. Time-Varying Volatilities
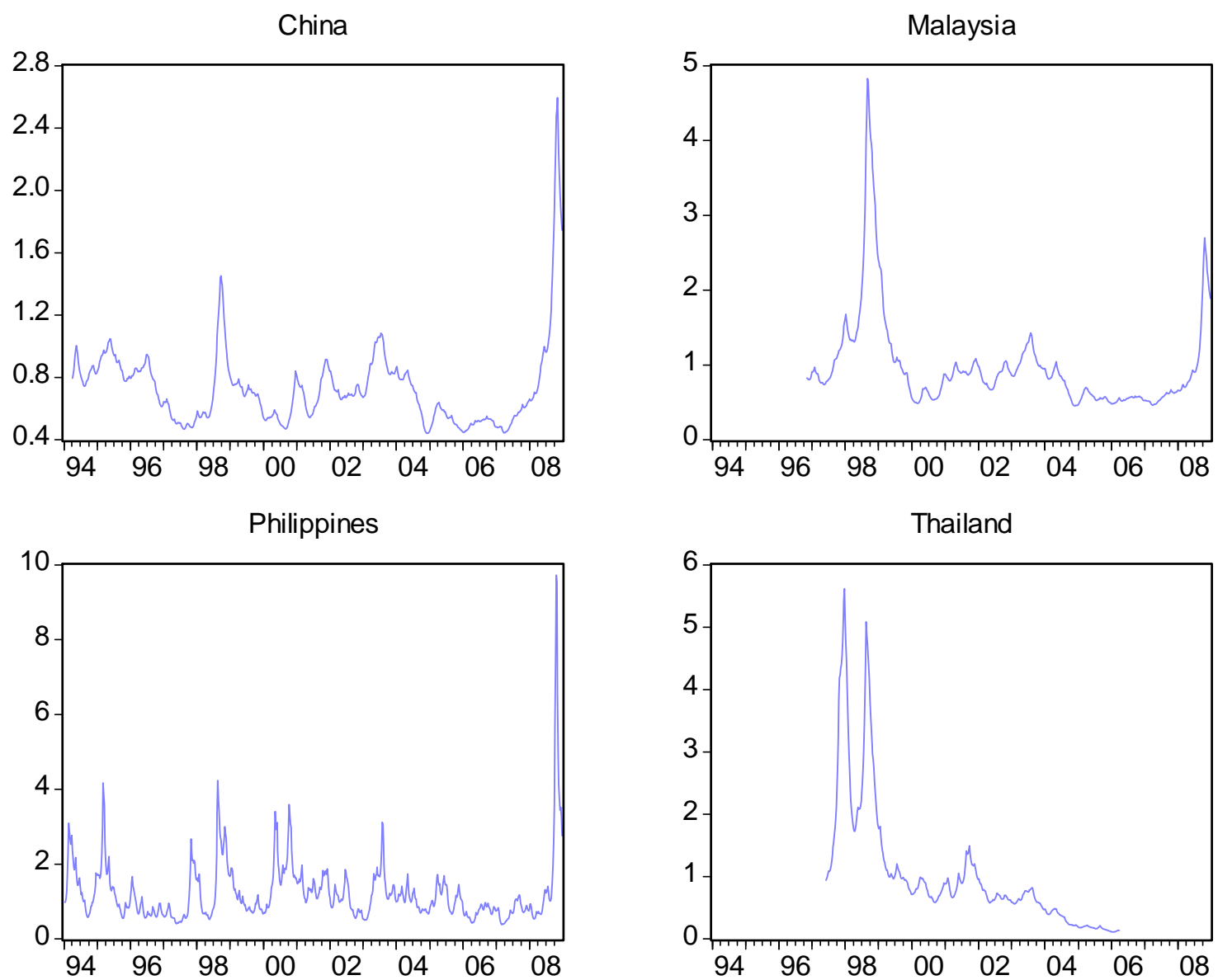
Figure 4. Time-Varying Correlations with World Equity Index
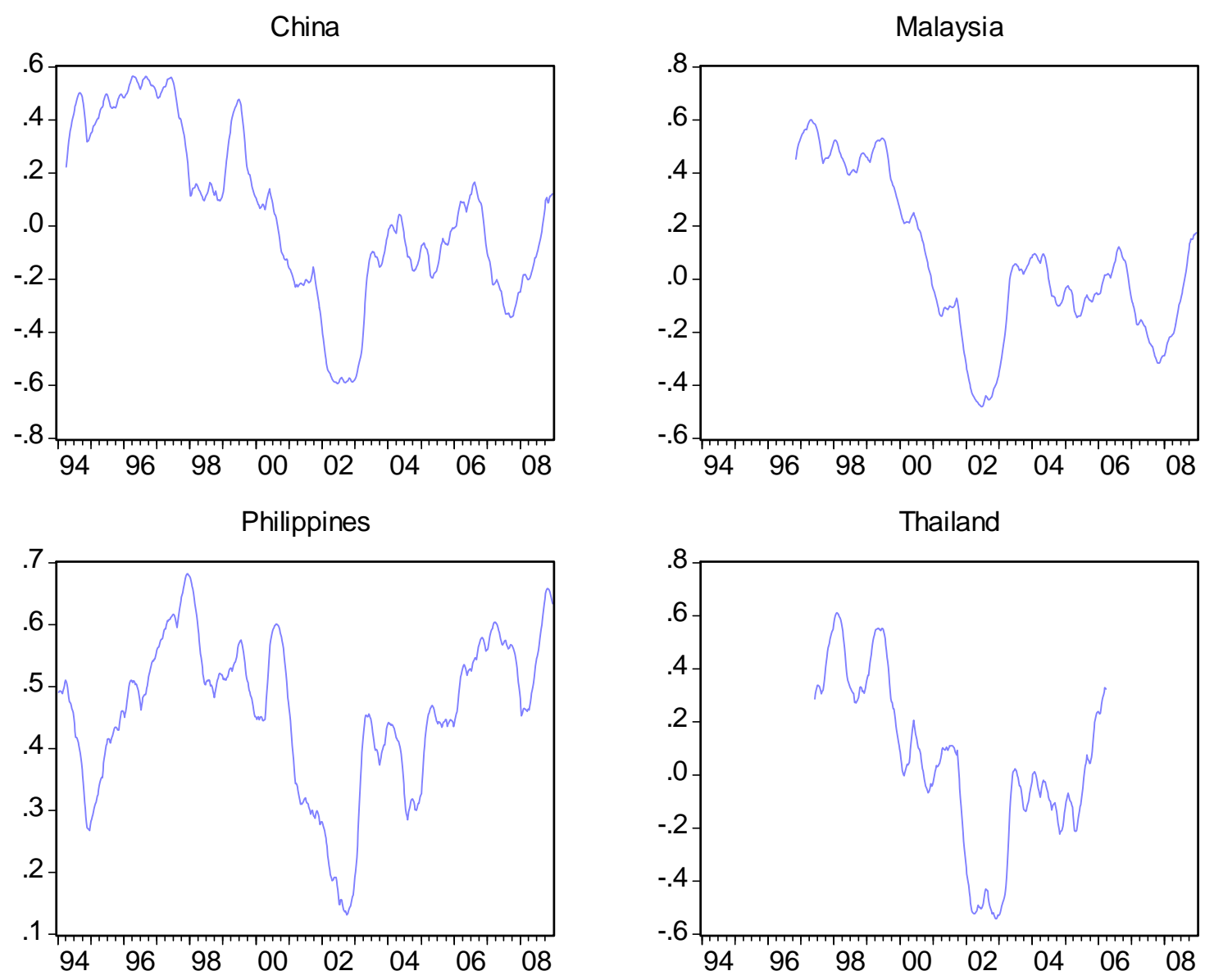
Figure 5. Time-Varying Betas
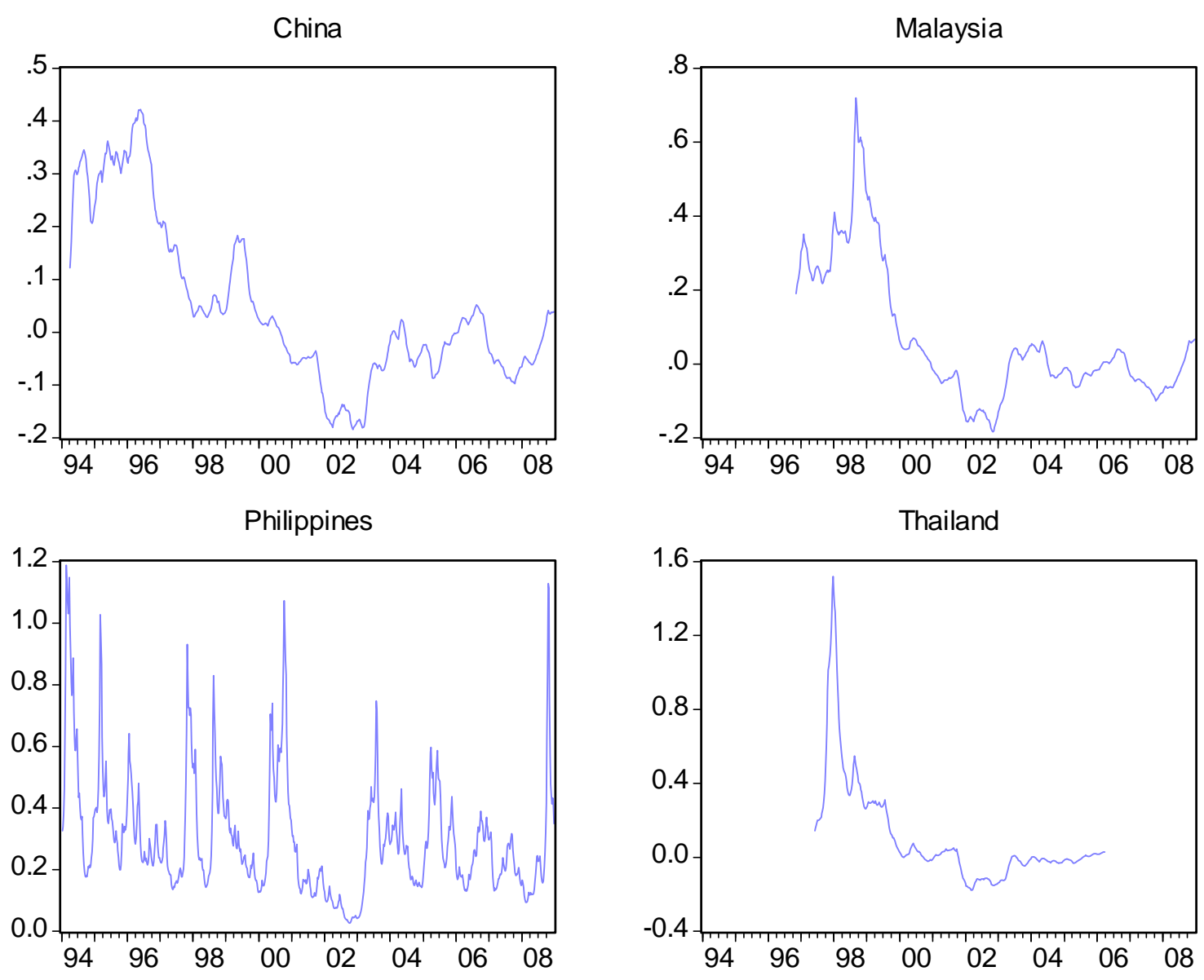
Figure 6. Time-Varying Betas - Local Currency
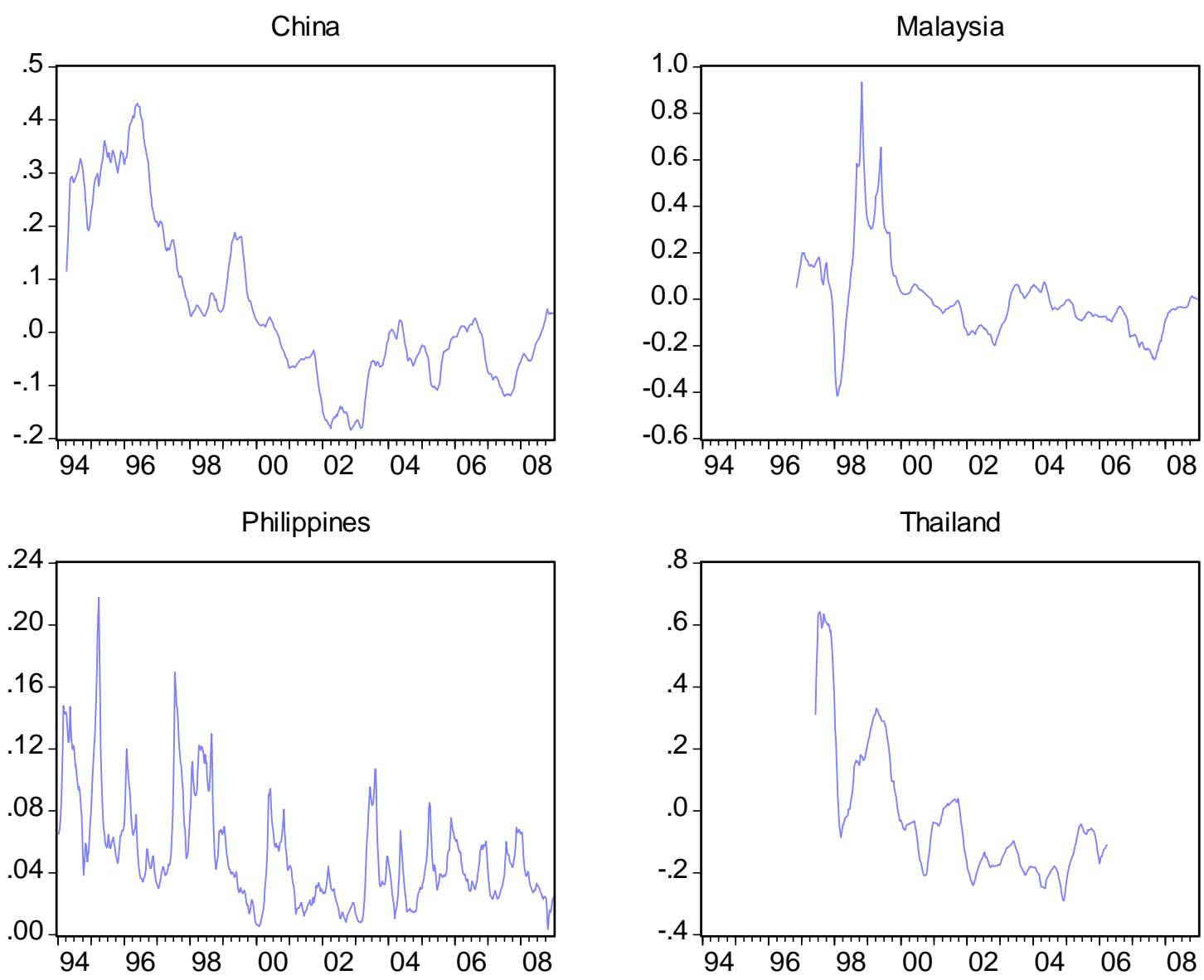
Table 1. Descriptive Statistics

\begin{tabular}{|c|c|c|c|c|}
\hline & China & Malaysia & Philippines & Thailand \\
\hline \multicolumn{5}{|c|}{ US Dollar-Denominated Series } \\
\hline Observations & 769 & 634 & 782 & 461 \\
\hline Mean & 0.148 & 0.138 & 0.179 & 0.144 \\
\hline Max & 8.243 & 7.904 & 21.290 & 8.305 \\
\hline Min & -7.122 & -12.937 & -19.902 & -13.663 \\
\hline Std. Dev. & 0.827 & 1.317 & 1.900 & 1.686 \\
\hline Skewness & 0.286 & -1.755 & -1.025 & -2.308 \\
\hline Kurtosis & 22.587 & 26.133 & 48.338 & 24.994 \\
\hline $\mathrm{JB}$ & $\begin{array}{r}12303.490 \\
(0.000)\end{array}$ & $\begin{array}{r}14461.610 \\
(0.000)\end{array}$ & $\begin{array}{r}67112.970 \\
(0.000)\end{array}$ & $\begin{array}{r}9700.650 \\
(0.000)\end{array}$ \\
\hline $\operatorname{LB}(10)$ & $\begin{array}{r}6.922 \\
(0.733)\end{array}$ & $\begin{array}{r}108.650 \\
(0.000)\end{array}$ & $\begin{array}{r}73.272 \\
(0.000)\end{array}$ & $\begin{array}{r}88.074 \\
(0.000)\end{array}$ \\
\hline LB2(10) & $\begin{array}{r}207.320 \\
(0.000)\end{array}$ & $\begin{array}{r}330.110 \\
(0.000)\end{array}$ & $\begin{array}{r}309.080 \\
(0.000)\end{array}$ & $\begin{array}{r}240.430 \\
(0.000)\end{array}$ \\
\hline LM ARCH(10) & $\begin{array}{r}244.563 \\
(0.000)\end{array}$ & $\begin{array}{r}204.749 \\
(0.000)\end{array}$ & $\begin{array}{r}224.615 \\
(0.000)\end{array}$ & $\begin{array}{r}106.899 \\
(0.000)\end{array}$ \\
\hline \multicolumn{5}{|c|}{ Local Currency-Denominated Series } \\
\hline Observations & 769 & 634 & 782 & 461 \\
\hline Mean & 0.116 & 0.188 & 0.248 & 0.241 \\
\hline Max & 8.039 & 36.084 & 21.147 & 12.423 \\
\hline Min & -6.986 & -22.945 & -18.017 & -14.082 \\
\hline Std. Dev. & 0.836 & 2.557 & 2.074 & 2.071 \\
\hline Skewness & 0.252 & 2.749 & -0.110 & -0.089 \\
\hline Kurtosis & 20.221 & 77.203 & 30.893 & 13.432 \\
\hline JB & $\begin{array}{r}9509.954 \\
(0.000)\end{array}$ & $\begin{array}{r}146251.000 \\
(0.000)\end{array}$ & $\begin{array}{r}25352.000 \\
(0.000)\end{array}$ & $\begin{array}{r}2090.933 \\
(0.000)\end{array}$ \\
\hline LB(10) & $\begin{array}{r}6.749 \\
(0.749)\end{array}$ & $\begin{array}{r}83.838 \\
(0.000)\end{array}$ & 55.521 & $\begin{array}{r}24.851 \\
(0.006)\end{array}$ \\
\hline LB2(10) & $\begin{array}{r}214.840 \\
(0.000)\end{array}$ & $\begin{array}{r}85.716 \\
(0.000)\end{array}$ & $\begin{array}{r}273.940 \\
(0.000)\end{array}$ & $\begin{array}{r}179.020 \\
(0.000)\end{array}$ \\
\hline LM ARCH(10) & $\begin{array}{r}232.913 \\
(0.000)\end{array}$ & $\begin{array}{r}81.162 \\
(0.000)\end{array}$ & $\begin{array}{r}224.615 \\
(0.000)\end{array}$ & $\begin{array}{r}84.805 \\
(0.000)\end{array}$ \\
\hline
\end{tabular}

Note: The table presents preliminary summary statistics for weekly log returns for the sovereign bond markets in each of the four countries. $\mathrm{LB}(10)$ and LB2(10) are the Ljung-Box statistics for the returns and squared returns with 10 lags. ARCH LM(10) is a Lagrange multiplier test for ARCH using 10 lags. JB is the Jarque-Bera statistic for normality. 
Table 2. Estimation Results

\begin{tabular}{|c|c|c|c|c|c|c|c|c|}
\hline & \multicolumn{4}{|c|}{ China } & \multicolumn{4}{|c|}{ Malaysia } \\
\hline & Mean & St. Dev. & $2.5 \%$ & $97.5 \%$ & Mean & St. Dev. & $2.5 \%$ & $97.5 \%$ \\
\hline$\gamma_{10}$ & -0.563 & 0.280 & -0.998 & 0.131 & -0.380 & 0.356 & -1.113 & 0.319 \\
\hline$\gamma_{20}$ & 0.767 & 0.490 & -0.325 & 1.502 & 1.375 & 0.247 & 0.831 & 1.831 \\
\hline$\gamma_{11}$ & 0.963 & 0.021 & 0.914 & 0.993 & 0.974 & 0.012 & 0.946 & 0.994 \\
\hline$\gamma_{22}$ & 0.983 & 0.016 & 0.941 & 0.999 & 0.959 & 0.025 & 0.900 & 0.995 \\
\hline$\delta_{0}$ & 0.435 & 0.387 & 0.941 & 0.999 & 1.009 & 0.600 & 0.023 & 2.224 \\
\hline$\delta_{1}$ & 0.984 & 0.011 & 0.956 & 1.309 & 0.989 & 0.011 & 0.960 & 0.999 \\
\hline$\sigma_{1}$ & 0.204 & 0.042 & 0.135 & 0.298 & 0.239 & 0.039 & 0.171 & 0.325 \\
\hline$\sigma_{2}$ & 0.164 & 0.043 & 0.098 & 0.263 & 0.204 & 0.049 & 0.122 & 0.311 \\
\hline \multirow[t]{3}{*}{$\sigma_{\rho}$} & 0.149 & 0.047 & 0.085 & 0.266 & 0.128 & 0.037 & 0.074 & 0.217 \\
\hline & \multicolumn{4}{|c|}{ Philippines } & \multicolumn{4}{|c|}{ Thailand } \\
\hline & Mean & St. Dev. & $2.5 \%$ & $97.5 \%$ & Mean & St. Dev. & $2.5 \%$ & $97.5 \%$ \\
\hline$\gamma_{10}$ & 0.023 & 0.202 & -0.371 & 0.429 & -0.268 & 0.623 & -1.387 & 1.054 \\
\hline$\gamma_{20}$ & 0.783 & 0.460 & -0.239 & 1.483 & 1.263 & 0.235 & 0.747 & 1.697 \\
\hline$\gamma_{11}$ & 0.887 & 0.031 & 0.819 & 0.941 & 0.988 & 0.008 & 0.970 & 0.999 \\
\hline$\gamma_{22}$ & 0.985 & 0.013 & 0.951 & 0.999 & 0.972 & 0.021 & 0.918 & 0.996 \\
\hline$\delta_{0}$ & 1.075 & 0.179 & 0.744 & 1.452 & 0.574 & 0.517 & -0.220 & 1.800 \\
\hline$\delta_{1}$ & 0.960 & 0.029 & 0.891 & 0.992 & 0.978 & 0.017 & 0.935 & 0.998 \\
\hline$\sigma_{1}$ & 0.572 & 0.072 & 0.442 & 0.722 & 0.298 & 0.054 & 0.206 & 0.417 \\
\hline$\sigma_{2}$ & 0.150 & 0.036 & 0.094 & 0.233 & 0.122 & 0.035 & 0.071 & 0.205 \\
\hline$\sigma_{\rho}$ & 0.125 & 0.036 & 0.071 & 0.210 & 0.184 & 0.059 & 0.098 & 0.325 \\
\hline
\end{tabular}

Note: The table presents results for the bivariate stochastic volatility model with dynamic correlation. Mean, standard deviation, and 95\% credible intervals of the posterior distributions are showed for each parameter. 
Table 3. Geweke Z-Score Test Results

\begin{tabular}{llccc}
\hline & China & Malaysia & Philippines & Thailand \\
\hline$\gamma_{10}$ & -1.527 & -0.611 & 0.626 & -0.119 \\
$\gamma_{20}$ & 0.606 & 0.130 & 0.720 & 0.547 \\
$\gamma_{11}$ & 0.343 & 1.564 & -1.301 & -0.490 \\
$\gamma_{22}$ & -1.324 & -1.461 & 1.079 & 0.483 \\
$\delta_{0}$ & -0.511 & -1.202 & 2.040 & 1.121 \\
$\delta_{1}$ & 0.630 & -0.214 & 2.302 & 0.169 \\
$\sigma_{1}$ & -0.561 & -1.318 & 0.928 & 0.793 \\
$\sigma_{2}$ & 1.764 & 1.844 & -1.505 & -0.390 \\
$\sigma_{\rho}$ & -0.868 & -0.106 & -1.038 & 0.946 \\
\hline
\end{tabular}

Note: Geweke Z-score test statistics for each model parameter. 
Table 4. Descriptive Statistics for Time-Varying Betas

\begin{tabular}{lrrrr}
\hline \multicolumn{1}{l}{ China } & \multicolumn{2}{l}{ Malaysia } & \multicolumn{1}{l}{ Philippines } & Thailand \\
& & & & \\
\hline & & & & \\
Observations & 769 & 634 & 781 & 461 \\
Mean & 0.048 & 0.065 & 0.302 & 0.103 \\
Max & 0.422 & 0.720 & 1.188 & 1.520 \\
Min & -0.184 & -0.184 & 0.026 & -0.178 \\
Std. Dev. & 0.152 & 0.179 & 0.194 & 0.279 \\
Skewness & 0.832 & 1.299 & 1.644 & 2.581 \\
Kurtosis & 2.742 & 4.108 & 6.444 & 10.768 \\
JB & 90.9 & 210.8 & 737.7 & 1670.8 \\
& $(0.000)$ & $(0.000)$ & $(0.000)$ & $0.000)$ \\
LB(10) & 7448.4 & 6048.6 & 3717.2 & 3928.9 \\
LB2(10) & $(0.000)$ & $(0.000)$ & $(0.000)$ & $(0.000)$ \\
& 7121.7 & 5286.0 & 2548.5 & 2881.4 \\
& $(0.000)$ & $(0.000)$ & $(0.000)$ & $(0.000)$
\end{tabular}

Note: The table presents preliminary summary statistics for sovereign bond betas. LB(10) and LB2(10) are the Ljung-Box statistics for the beta and squared betas with 10 lags. JB is the Jarque-Bera statistic for normality. 
Table 5. Estimation Results - Local Currency

\begin{tabular}{|c|c|c|c|c|c|c|c|c|}
\hline & \multicolumn{4}{|c|}{ China } & \multicolumn{4}{|c|}{ Malaysia } \\
\hline & Mean & St. Dev. & $2.5 \%$ & $97.5 \%$ & Mean & St. Dev. & $2.5 \%$ & $97.5 \%$ \\
\hline$\gamma_{10}$ & -0.539 & 0.284 & -0.972 & 0.162 & 0.004 & 0.480 & -1.001 & 0.920 \\
\hline$\gamma_{20}$ & 0.722 & 0.506 & -0.369 & 1.481 & 1.389 & 0.243 & 0.856 & 1.852 \\
\hline$\gamma_{11}$ & 0.962 & 0.021 & 0.913 & 0.993 & 0.976 & 0.011 & 0.950 & 0.994 \\
\hline$\gamma_{22}$ & 0.984 & 0.015 & 0.944 & 0.999 & 0.960 & 0.024 & -0.404 & 0.995 \\
\hline$\delta_{0}$ & 0.397 & 0.384 & -0.264 & 1.265 & 0.158 & 0.429 & 0.925 & 1.286 \\
\hline$\delta_{1}$ & 0.985 & 0.010 & 0.960 & 0.998 & 0.973 & 0.019 & 0.960 & 0.998 \\
\hline$\sigma_{1}$ & 0.206 & 0.041 & 0.139 & 0.298 & 0.330 & 0.050 & 0.242 & 0.439 \\
\hline$\sigma_{2}$ & 0.160 & 0.042 & 0.097 & 0.258 & 0.203 & 0.049 & 0.120 & 0.310 \\
\hline \multirow[t]{3}{*}{$\sigma_{\rho}$} & 0.150 & 0.041 & 0.088 & 0.248 & 0.151 & 0.044 & 0.086 & 0.260 \\
\hline & \multicolumn{4}{|c|}{ Philippines } & \multicolumn{4}{|c|}{ Thailand } \\
\hline & Mean & St. Dev. & $2.5 \%$ & $97.5 \%$ & Mean & St. Dev. & $2.5 \%$ & $97.5 \%$ \\
\hline$\gamma_{10}$ & 0.573 & 0.302 & 0.028 & 1.229 & 2.977 & 0.513 & 1.957 & 3.984 \\
\hline$\gamma_{20}$ & 0.898 & 0.433 & -0.136 & 1.550 & 1.258 & 0.236 & 0.737 & 1.691 \\
\hline$\gamma_{11}$ & 0.950 & 0.018 & 0.911 & 0.981 & 0.997 & 0.003 & 0.989 & 1.000 \\
\hline$\gamma_{22}$ & 0.981 & 0.016 & 0.940 & 0.999 & 0.972 & 0.021 & 0.917 & 0.997 \\
\hline$\delta_{0}$ & 0.133 & 0.084 & -0.032 & 0.298 & 0.196 & 0.510 & -0.578 & 1.360 \\
\hline$\delta_{1}$ & 0.823 & 0.106 & 0.559 & 0.964 & 0.977 & 0.019 & 0.929 & 0.998 \\
\hline$\sigma_{1}$ & 0.386 & 0.052 & 0.294 & 0.496 & 0.182 & 0.043 & 0.111 & 0.278 \\
\hline$\sigma_{2}$ & 0.169 & 0.042 & 0.105 & 0.266 & 0.120 & 0.036 & 0.068 & 0.208 \\
\hline$\sigma_{\rho}$ & 0.105 & 0.034 & 0.060 & 0.191 & 0.171 & 0.055 & 0.086 & 0.299 \\
\hline
\end{tabular}

Note: The table presents results for the bivariate stochastic volatility model with dynamic correlation. Mean, standard deviation, and 95\% credible intervals of the posterior distributions are showed for each parameter. 
Table 6. Descriptive Statistics for Time-Varying Betas - Local Currency

\begin{tabular}{lrrrr}
\hline & \multicolumn{1}{l}{ China } & \multicolumn{1}{l}{ Malaysia } & \multicolumn{1}{l}{ Philippines } & Thailand \\
& & & & \\
\hline & & & 781 & 461 \\
Observations & 769 & 634 & 0.042 & -0.073 \\
Mean & 0.005 & -0.031 & 0.218 & 0.642 \\
Max & 0.431 & 0.933 & 0.004 & -0.290 \\
Min & -0.184 & -0.416 & 0.034 & 0.213 \\
Std. Dev. & 0.153 & 0.180 & 1.356 & 1.511 \\
Skewness & 0.823 & 1.539 & 5.078 & 4.789 \\
Kurtosis & 2.729 & 7.042 & 379.8 & 237.0 \\
JB & 89.1 & 682.0 & $(0.000)$ & $(0.000)$ \\
& $(0.000)$ & $(0.000)$ & 4865.7 & 3907.1 \\
LB(10) & 7448 & 5192 & $(0.000)$ & $(0.000)$ \\
& $(0.000)$ & $(0.000)$ & 3798.1 & 3391.4 \\
LB2(10) & 7101.1 & 3228.5 & $(0.000)$ & $(0.000)$ \\
& $(0.000)$ & $(0.000)$ & & \\
& & & &
\end{tabular}

Note: The table presents preliminary summary statistics for sovereign bond betas. $\mathrm{LB}(10)$ and LB2(10) are the Ljung-Box statistics for the beta and squared betas with 10 lags. JB is the Jarque-Bera statistic for normality. 